\title{
POLÍTICAS EDUCACIONAIS E EDUCAÇÃO INTERCULTURAL: IMPLICAÇÕES SOBRE OS CURRÍCULOS ESCOLARES E CONSTRUÇÃO DE IDENTIDADES DESCOLONIZADAS
}

EDUCATIONAL POLICIES AND INTERCULTURAL EDUCATION: IMPLICATIONS ON SCHOOL CURRICULA AND THE CONSTRUCTION OF DECOLONIZED IDENTITIES

\section{POLÍTICAS EDUCACIONALES Y LA EDUCACIÓN INTERCULTURAL: IMPLICACIONES SOBRE LOS CURRÍCULOS ESCOLARES Y CONSTRUCCIÓN DE IDENTIDADES DESCOLONIZADAS}

Filomena Lucia Gossler Rodrigues da Silva ${ }^{1}$ Sonia Regina de Souza Fernandes ${ }^{2}$ Sadi José Rodrigues da Silva ${ }^{3}$

\section{RESUMO}

A observação de uma crescente sensibilização quanto à necessidade de realizarmos práticas pedagógicas interculturais para uma educação mais inclusiva com relação aos grupos historicamente subalternizados motivou-nos a reflexão neste artigo. Nos textos das políticas educacionais, especialmente aqueles produzidos a partir de discussões ocorridas na segunda metade da primeira década e primeira metade da segunda década dos anos 2000, verificamos avanços das perspectivas interculturais e inclusivas. É nesse contexto que se situa este trabalho. Seu objetivo é, a partir da análise das Diretrizes Curriculares Nacionais Gerais para a Educação Básica (Resolução CNE/CEB n. ${ }^{\circ}$ 4/2010), Diretrizes Curriculares Nacionais para o Ensino Médio (Resolução CNE/CEB n. ${ }^{\circ}$ 2/2012) e das Diretrizes Curriculares Nacionais para a Educação Profissional Técnica de Nível Médio (Resolução CNE/CEB n. ${ }^{\circ}$ 6/2012), $\underline{\text { refletir sobre a potencialidade de essas legislações subsidiarem a elaboração de currículos e o }}$

\footnotetext{
1 Doutora em Educação pela Universidade Federal de Santa Catarina. Professora de Educação Básica, Técnica e Tecnológica do Instituto Federal de Educação, Ciência e Tecnologia Catarinense - Campus Camboriú. E-mail: $<$ filomena.silva@ifc.edu.br>.

2 Doutora em Educação pela Universidade do Vale dos Sinos/RS. Professora de Educação Básica, Técnica e Tecnológica do Instituto Federal de Educação, Ciência e Tecnologia Catarinense - Campus Camboriú. E-mail: <sonia.fernandes@ifc.edu.br>.

3 Doutorando em Educação pela Universidade Federal de Santa Catarina. Professor da Rede Estadual de Santa Catarina.E-mail:<sadijoserodriguesdasilva@gmail.com>.
} 
desenvolvimento de práticas interculturais e inclusivas. Espera-se, ainda, que esses documentos impactem a construção de identidades descolonizadas, tanto de professores quanto de estudantes, de forma a contribuir para uma formação emancipatória dos sujeitos do processo educativo.

PALAVRAS-CHAVE: Políticas educacionais. Educação intercultural. Identidades descolonizadas.

\begin{abstract}
The observation of a growing awareness about the need to accomplish intercultural pedagogical practices for a more inclusive education regarding historically subalternized groups motivated the reflections brought on in this article. In educational policy texts, especially those produced from discussions taken place in the second half of the first decade and the first half of the second decade of the 2000s, we see improvements in intercultural and inclusive perspectives. It is in this context that this research paper is situated. Its objective is, from the analysis of the General National Curricular Guidelines for Basic Education (CNE CEB Resolution n. ${ }^{\circ}$ 4/2010), National Curricular Guidelines for Secondary Education (Resolution CNE/CEB n..$^{\circ}$ 2/2012), and the National Curricular Guidelines for (CNE/CEB Resolution n. ${ }^{\circ}$ 6/2012), think over the potentiality of these legislations on subsidizing the elaboration of curriculum and the development of intercultural and inclusive practices. Hopes are yet that these documents impact on the construction of decolonized identities of both teachers as well as the students in order to contribute to an emancipatory formation of the agents of educative process.
\end{abstract}

KEYWORDS: Educational policies. Intercultural education. Decolonized identities.

\title{
RESUMEN
}

La observación de una cresciente sensibilidad cuanto a la necesidad de realizarmos prácticas pedagógicas interculturales que contribuyan para que se alcance una educación mas inclusiva en relación a los grupos historicamente subalternizados, nos ha motivado a hacer una reflexión en este artículo. Los textos de las políticas educacionales, especialmente aquellos producidos a partir de discuciones realizadas en la segunda mitad de la primera década y primera mitad de la segunda década de los años 2000, se puede observar avances de las 
perspectivas interculturales e inclusivas. En ese contexto es que se ubica esta reflexión. El objetivo es, a partir del análisis de las Directrices Curriculares Nacionales Generales para la Educación Básica (Resolución CNE/CEB n. ${ }^{\circ}$ 4/2010), Diretrices Curriculares Nacionales para la Enseñanza del Bachillerato (Resolución CNE/CEB n. ${ }^{\circ}$ 2/2012) y las Directrices Curriculares Nacionales para la Educación Profesional Técnica de nivel de Bachillerato (Resolución CNE/CEB n. ${ }^{\circ}$ 6/2012), reflexionar sobre la potencialidad de estas legislaciones puedan dar subsídios para la elaboración de currículos y el desarrollo de prácticas interculturales e inclusivas que impacten en la construcción de identidades descolonizadas para professores así como para estudiantes de forma que se contribuya para una formación de emancipación de los sujetos del proceso educativo.

PALABRAS CLAVE: Políticas educacionales. Educación intercultural. Identidades descolonizadas.

\section{INTRODUÇÃO}

A problemática contemporânea trazida pelo/no título deste artigo, Políticas educacionais e educação intercultural: implicações sobre os currículos escolares e construção de identidades descolonizadas, tem ocupado cada vez mais espaço nos debates que se colocam contra os discursos conservadores e neoliberais em torno da Educação e do papel do Estado. Nesse sentido, as reflexões aqui realizadas, cientes dessa ressonância, em grande medida conquistada por meio de $\operatorname{slogans}^{4}$ ressemantizados, visam reforçar que tal temática requer cuidado com a utilização de termos/conceitos que nos possibilitem demarcar ou marcar o "lugar" de onde "falamos".

Assim, defendemos o Estado como provedor de uma educação de qualidade social referenciada que tem como compromisso construir e implementar currículos, tanto para a educação básica quanto para a formação dos seus professores, que promovam práticas pedagógicas interculturais. Ao mesmo tempo, é preciso desenvolver ações que contribuam

\footnotetext{
4 De acordo com Fernandes (2016, p. 30), a utilização de termos de forma descontextualizada pode tornar-se um slogan, como alerta Contreras (2002), uma vez que parece comum usá-los indiscriminadamente, em especial, no campo da educação. Esse fato, segundo o autor, produz um desgaste de seu significado, assim como esconde ou confunde diferentes pretensões e sentidos. Ainda nessa direção, Afonso (2004) chama atenção para o processo atual de ressemantização dos termos/conceitos, uma vez que se pode dizer algo que assume formas diferentes, em situações convenientes.
} 
para uma educação mais inclusiva aos grupos historicamente subalternizados. Desse modo, são necessárias não somente políticas educacionais que induzam tais práticas como modelos de gestão da educação que estimulem a constituição/instituição de escolas democráticas, como espaços legítimos de educação integral e de processos emancipatórios. Para tanto, recorremos aos argumentos de Apple e Beane (1997, p. 11) no sentido de alertar que, em meio aos "ataques gerais à educação, temos de manter viva a longa tradição da reforma educacional democrática que desempenhou o papel importantíssimo de fazer de muitas escolas lugares cheios de vitalidade e força para aqueles que as frequentam". Do mesmo modo, faz-se necessário defender que, “em vez de renunciar à ideia das escolas públicas e descer a estrada que leva à privatização, precisamos nos concentrar nas escolas que dão certo" (APPLE; BEANE, 1997, p. 11).

Diante do exposto, este artigo visa identificar em alguns dos textos das políticas educacionais brasileiras, especialmente daquelas implantadas no período de 2010 a 2012 , as discussões anteriores promovidas pelo Ministério da Educação e pelo Conselho Nacional de Educação, no sentido de assegurar a participação da sociedade na atualização de diretrizes para a Educação brasileira. Tal participação, segundo o documento "Diretrizes para a Educação Básica", publicado em 2013, ocorreu por meio de "uma série de estudos, debates, seminários e audiências públicas que contaram com a participação dos sistemas de ensino, dos órgãos educacionais e sociedade civil” (BRASIL, 2013 p. 4). No documento mencionado, identificamos o envolvimento na elaboração das diretrizes para a educação básica de: membros do Conselho Nacional de Educação; representantes dos conselhos estaduais e municipais; técnicos e servidores do CNE; especialistas, pesquisadores e integrantes de sistemas de ensino; técnicos do Ministério da Educação; e representantes de entidades representativas dos trabalhadores em educação participantes dos seminários, debates e audiências públicas.

$\mathrm{Na}$ introdução do referido documento, o então Ministro da Educação, Sr. Aloísio Mercadante, sinaliza que a Educação Básica de qualidade deve ser vista como "um direito assegurado pela Constituição Federal e pelo Estatuto da Criança e do Adolescente" (BRASIL, 2013, p. 4), sobretudo como um dos fundamentos de um projeto de Nação. Para tanto, a formação realizada pelas escolas constitui-se, continua o ex-Ministro, em um "alicerce indispensável e condição primeira para o exercício pleno da cidadania e o acesso aos direitos 
sociais, econômicos, civis e políticos", devendo "proporcionar o desenvolvimento humano na sua plenitude, em condições de liberdade e dignidade, respeitando e valorizando as diferenças" (BRASIL, 2013, p. 4).

Assim, visando identificar os possíveis avanços das perspectivas interculturais e inclusivas presentes em algumas das Diretrizes da Educação Básica Brasileira, tomaremos para a análise e reflexão deste texto as Diretrizes Curriculares Nacionais Gerais para a Educação Básica (Resolução CNE/CEB n. ${ }^{\circ}$ 4/2010), as Diretrizes Curriculares Nacionais para o Ensino Médio (Resolução CNE/CEB n. ${ }^{\circ}$ 2/2012) e as Diretrizes Curriculares Nacionais para a Educação Profissional Técnica de Nível Médio (Resolução CNE/CEB n. ${ }^{\circ}$ 6/2012).

Metodologicamente, além de uma fundamentação teórica realizada com o aporte na literatura acerca da temática, lançamos mão da análise documental das diretrizes mencionadas. Desse modo, visamos fundamentar a reflexão acerca da potencialidade de estas subsidiarem a elaboração de currículos e o desenvolvimento de práticas interculturais e inclusivas que impactem a construção de identidades descolonizadas, tanto de professores quanto de estudantes, contribuindo para uma formação comprometida com a emancipação dos sujeitos do processo educativo.

\section{CURRÍCULOS E PRÁTICAS INTERCULTURAIS E INCLUSIVAS: CONTRIBUIÇÕES PARA A CONSTRUÇÃO DE IDENTIDADES DESCOLONIZADAS}

A contribuição da escola na construção de identidades descolonizadas está no desenvolvimento de práticas pedagógicas que possibilitem a reflexão sobre o contexto sociocultural, econômico e político em que os estudantes e suas famílias estão inseridos. Tem papel também na construção de espaços democráticos que propiciem a vivência da cidadania plena, na criação de oportunidades para que todos possam se sentir pertencentes e sujeitos não somente do seu processo de ensino e aprendizagem, mas também das transformações do contexto em que estão incluídos. Tal processo exige, sobretudo, concepções e práticas pedagógicas interculturais e inclusivas, que questionam a lógica colonizadora eurocêntrica do processo de construção dos conhecimentos. 
Em vista do exposto, assumimos a concepção de interculturalidade a partir da perspectiva crítica, que "traduz a reivindicação de povos e grupos sociais historicamente subalternizados; representa também setores de luta a eles associados, na construção de uma sociedade justa, equitativa, igualitária e plural” (COPPETE; FLEURI; STOLTZ, 2012, p. 243244).

Assumir essa perspectiva de interculturalidade requer um posicionamento epistemológico de desobediência aos padrões eurocêntricos e capitalcêntricos (de interesse do sistema produtivo capitalista), o que demanda inquirirmos constantemente a realidade. Faz-se necessário adotar como princípio e como prática concepções mais inclusivas que possam corroborar os processos de emancipação dos grupos sociais historicamente subalternizados, os quais têm suas identidades sociais forjadas sob uma perspectiva colonialista. Para tanto, tem se tornado cada vez mais urgente e essencial refletir e descortinar o processo de fabricação de uma identidade "natural" dos povos em todo o mundo, nos mais diversos âmbitos, tais como: educacionais, políticos, culturais, científicos e econômicos. Em perspectiva histórica, a política de identidade dos seres humanos que detêm o poder possui, segundo Mignolo (2008, p. 289), as seguintes caraterísticas: branco, heterossexual e do sexo masculino. De acordo com o autor,

[...] a identidade em política é crucial para a opção descolonial, uma vez que, sem a construção de teorias políticas e a organização de ações políticas fundamentadas em identidades que foram alocadas [...] por discursos imperiais [...], pode não ser possível desnaturalizar a construção racial e imperial da identidade no mundo moderno em uma economia capitalista. As identidades construídas pelos discursos europeus modernos eram raciais (isto é, a matriz racial colonial) e patriarcais. (MIGNOLO, 2008, p. 289-290 - grifos do autor).

Os discursos liberais intensificados nos últimos anos vêm propagando a necessidade de políticas de austeridade sob o argumento de que elas são indispensáveis para que, no futuro, tenhamos a diminuição das injustiças, das desigualdades e da corrupção. Tais discursos, difundidos indiscriminadamente pela mídia, objetivam construir imaginários nos grupos sociais subalternizados de um período de crise econômica severa cujo combate envolve a compreensão e o esforço da população, de modo a evitar a falência do Estado. A forma como as políticas em curso no Brasil e em boa parte dos países latinos está sendo divulgada pelos meios de comunicação, camuflando realidades e as razões da crise, dissemina a necessidade de reformas que retiram direitos sociais básicos dos trabalhadores, conquistados 
por meio de lutas em décadas anteriores. Tal disseminação tem sido feita de modo a constituir-se em um exemplo primoroso de como o Estado opera sobre a construção da identidade do seu povo.

\begin{abstract}
A produção da identidade envolve o Estado, através dos seus regulamentos, serviços, encontros políticos, discursos públicos, programas de formação etc. É uma componente essencial do sistema, fabricada para gerir problemas de ordem pública e de regulamentação. [...] A identidade é "produzida" através de um discurso que, simultaneamente, explica e constrói o sistema (LAWN, 2001, p. 118).
\end{abstract}

Considerada tal perspectiva, tem se mostrado cada vez mais necessário o enfrentamento dessa realidade, combatendo a forma como o Estado vem operando na fabricação de identidades colonizadas por meio das concepções imperialistas. É preciso buscar formas de mobilização para construir espaços de resistência, tendo como horizonte uma sociedade menos injusta. Portanto, convergimos com Mignolo (2008), no sentido de que é fundamental pensar descolonialmente, criando uma nova identidade em política que permita subverter a razão imperial de uma identidade que se afirma "superior ao construir construtos inferiores (raciais, nacionais, religiosos, sexuais, de gênero), e de expeli-los para fora da esfera normativa do "real'” (MIGNOLO, 2008, p. 291). Subverter essa razão imperial e eurocêntrica ${ }^{5}$ exige, segundo o autor, pensar politicamente projetos de descolonização.

Atuar na perspectiva de construir projetos e práticas que possam se converter em espaços de resistência às concepções imperialistas/eurocêntricas e capitalcêntricas constitui-se em uma das estratégias necessárias que estão no horizonte das nossas possibilidades. Essas práticas precisam estar comprometidas com uma sociedade menos injusta e, portanto, mais inclusiva. É a partir dessa compreensão que entendemos que descolonizar as práticas pedagógicas significa simultaneamente "desvelar a lógica da colonialidade e da reprodução da matriz colonial do poder (que, é claro, significa uma economia capitalista); e desconectar-se dos efeitos totalitários das subjetividades e categorias de pensamento ocidentais [...]" (MIGNOLO, 2008, p. 313).

Diante do exposto, trabalhar na perspectiva intercultural e, portanto, descolonizar as práticas pedagógicas envolve a implementação de

5 De acordo com Mignolo (2008, p. 301), o Eurocentrismo não dá nome a um local geográfico, mas à hegemonia de uma forma de pensar fundamentada no grego e no latim e nas seis línguas europeias e imperiais da modernidade, ou seja, modernidade/colonialidade. 
[...] um projeto cujo objetivo é a intervenção nas mudanças induzidas a partir do contato e da interação entre sujeitos e sua diversidade, de maneira que promova atitudes abertas ao confronto e conduza processos integradores entre culturas (COPPETE; FLEURI; STOLTZ, 2012, p. 239-240).

Compreendemos, a partir das reflexões realizadas, que, se temos como horizonte o desenvolvimento de uma educação intercultural e inclusiva de forma que possamos caminhar em direção a uma sociedade mais justa, então, necessitamos, "tanto em termos de princípios quanto de ações, contribuir ao máximo para o benefício daqueles que estão em situação de desvantagens" (APPLE, 2006, p. 45). Assim, entendemos que a apropriação dos princípios contidos nos textos políticos das Diretrizes da Educação Brasileira, em vigor neste momento, pode contribuir para que nossas ações se comprometam com os interesses daqueles que estão em "situação de desvantagem", aqueles que, historicamente, têm estado em uma condição de subalternidade, seja por questões culturais, sociais, de etnia, de gênero, entre outras.

\section{CONCEPÇÕES DE INTERCULTURALIDADE, INCLUSÃO E EMANCIPAÇÃO PRESENTES NAS DIRETRIZES CURRICULARES PARA A EDUCAÇÃO BÁSICA}

O século XX, segundo Santomé (2013), é denominado como o século do reconhecimento dos Direitos Humanos dos Direitos dos Povos. Mesmo que muitos direitos conquistados em forma de leis, documentos, tratados e acordos ainda não tenham sido alcançados, é importante ressaltar que as conquistas feitas entre os séculos XX e XXI resultam de lutas sociais.

Catherine Walsh (2012), em seu artigo "Interculturalidad y (de)colonialidad: Perspectivas críticas y políticas", menciona que, em nosso continente, as discussões acerca da interculturalidade estão presentes nas políticas públicas, nas reformas educacionais e constitucionais e constituem-se em:

[...] um eixo importante tanto na esfera nacional-institucional quanto na esfera/cooperação inter/transnacional. Embora se possa argumentar que essa presença é um efeito e resultado das lutas dos movimentos político-político-ancestral e suas demandas de reconhecimento, direitos e transformação social, também pode ser vista, ao mesmo tempo, de outra perspectiva: a que liga para projetos globais de poder, capital e mercado (WALSH, 2012, p. 62). 
No que se refere às políticas públicas de Educação no Brasil, Coppete, Fleuri e Stoltz (2012) informam-nos que a preocupação com a discussão da diversidade cultural é bastante recente. Passou a ganhar terreno principalmente a partir do final dos anos 1990, articulada com as discussões de gênero, raça e etnia, e pode identificada, por exemplo, na

[...] incorporação da pluralidade cultural como tema transversal nos Parâmetros Curriculares Nacionais; a definição de um capítulo específico para abordar a educação especial; assim como os artigos voltados à educação indígena na Lei de Diretrizes e Bases da Educação Nacional LDB - n. 9.394/96; o Plano Nacional de Educação de 2001, com capítulos destinados à educação especial e educação indígena; a definição do dia 20 de novembro como dia da Consciência Negra; além da Lei n. 10.639/03 e Lei n. 11.645/08, já citadas e comentadas anteriormente (COPPETE; FLEURI; STOLTZ, 2012, p. 234-235).

Não obstante a presença desses conceitos nos documentos oficiais, entendemos que a implementação de uma perspectiva de educação intercultural e inclusiva, que tenha como horizonte a transformação social e a emancipação dos sujeitos, ainda possui um longo caminho a percorrer para instituir-se como práxis dos sistemas de ensino. Há que se mencionar, no entanto, que essas discussões têm alcançado espaço entre profissionais e em instituições comprometidas com os interesses daqueles que foram/são historicamente subalternizados com relação ao acesso aos direitos sociais básicos.

Dessarte, importa salientar que "as políticas educacionais vinculam-se e se comprometem com diferentes manifestações da política social e, como tal, configuram-se em um movimento contraditório entre as forças sociais em disputa no país” (SILVA, 2014, p. 97). A partir de tal afirmação, facilita-nos a compreensão de que a existência de forças sociais em disputa na constituição das políticas públicas é fundamental para se forjar um determinado projeto societário, influenciando, conforme sinaliza Lawn (2001), a fabricação da identidade da população. Assim, entendemos que as políticas educacionais possuem um papel estratégico na construção da identidade de um povo. Garantir ou negar uma sólida formação para a população é condição indispensável para conformar um projeto societário de nação, seja ele comprometido com os interesses do capital, via negação desse direito, ou com os interesses da classe trabalhadora mais empobrecida, por meio da garantia dessa formação.

Retomando os objetivos deste trabalho, ao iniciarmos a análise, observamos nos documentos mencionados que eles trazem um referencial legal e conceitual que apresenta os prin- 
cípios que orientam cada uma das diretrizes. Na Resolução CNE/CEB n. ${ }^{\circ} 4 / 2010$, que define Diretrizes Curriculares Nacionais Gerais para a Educação Básica (DCNEB), tais princípios estão presentes em seu art. $4{ }^{\circ}$.Este artigo estabelece que é princípio desse documento (síntese entre a Constituição Federal de 1988 e a Lei de Diretrizes e Bases da Educação Nacional, Lei n. ${ }^{0}$ 9.394/1996) que um projeto nacional de educação é responsabilidade do poder público, com a família, a sociedade e a escola. Entendemos que uma educação construída dialogicamente entre os segmentos envolvidos no processo educativo converge para uma concepção de educação intercultural e inclusiva.

Além disso, consideramos que, ao propor a universalização do acesso e permanência na escola, a implementação da legislação mencionada exige a criação de políticas de ações afirmativas que possam contribuir para o alcance desse propósito (bolsa família; sistema de cotas para ingresso em instituições públicas destinadas a afrodescendentes, indígenas e estudantes oriundos de escolas públicas; bolsa permanência, auxílio-alimentação, entre outras). ${ }^{6}$ Outro princípio observado na Resolução CNE/CEB n. ${ }^{\circ}$ 4/2010 é fazer da escola um lugar onde os envolvidos no processo de ensino e aprendizagem possuam liberdade de aprender, de ensinar, de pesquisar e divulgar a cultura, o pensamento, a arte, o saber e o pluralismo de ideias e concepções pedagógicas. Nesse contexto, não é aceitável, portanto, a defesa de projetos como "Escola sem Partido" ou nos quais o componente curricular de Ensino Religioso, por exemplo, seja ministrado a partir de um vínculo específico com uma determinada religião. Por fim, é princípio dessa Diretriz que a gestão da escola pública seja democrática, que haja vinculação entre a educação escolar, o trabalho e a prática social.

Igualmente, a Resolução n. ${ }^{\circ}$ 2/2012, que define as Diretrizes Curriculares Nacionais para o Ensino Médio (DCNEM), apresenta como referencial legal e conceitual que a última etapa da educação básica seja um direito social de cada pessoa. O documento destaca ainda que é dever do Estado sua oferta pública e gratuita a todos (art. 3. ${ }^{\circ}$ ). No tocante às formas de

6 Políticas que visam reduzir a desigualdade de acesso e permanência dos grupos socialmente excluídos na Educação Básica e Ensino Superior públicos do Brasil.

7 Projeto de Lei de 2015 que objetiva eliminar discussões de caráter ideológico do ambiente escolar das escolas brasileiras, restringindo o ensino dos conteúdos a uma pretensa ideia de neutralidade do conhecimento. Tal projeto contraria o princípio constitucional do pluralismo de ideias e de concepções pedagógicas, assim como o da liberdade de aprender, ensinar, pesquisar e divulgar o pensamento, a arte e o saber, considerando válidos apenas os conteúdos que servem à manutenção do status quo e doutrinários aqueles que apresentam uma visão crítica acerca do conhecimento e da realidade, ferindo inclusive a ideia de produção de sentido e de significado da aprendizagem, assim como da prática social. Diante da pressão da sociedade, tal projeto, que se encontrava na câmara dos deputados para apreciação e aprovação, foi arquivado no final do ano de 2017. 
oferta e organização do Ensino Médio (art. 5. ${ }^{\circ}$ ), observamos uma grande preocupação com a formação integral dos estudantes. Para tanto, além de mencionar o trabalho como princípio educativo e a pesquisa como um princípio pedagógico da formação, destaca a necessidade de se tomar como elemento fundamental a educação em direitos humanos; a sustentabilidade ambiental; a indissociabilidade entre a educação e a prática social; a integração e a contextualização dos conhecimentos, de modo que os conteúdos possam ser apropriados pelos estudantes com sentido e significado para vida; o reconhecimento e a aceitação da diversidade e da realidade concreta dos estudantes; e a organização curricular a partir de quatro dimensões importantes: o trabalho, a ciência, a cultura e a tecnologia.

Considerado o exposto, compreendemos que, assim como a Resolução CNE/CEB n. ${ }^{\circ}$ 4/2010, a Resolução CNE/CEB n. ${ }^{\circ}$ 2/2012 possui referenciais conceituais e legais que sustentam uma educação intercultural, inclusiva e emancipatória, uma vez que se propõe a realizar a formação integral dos estudantes. Vale mencionar, contudo, que é indispensável que os profissionais da educação não somente conheçam o disposto nessa resolução, como também façam "o exercício de uma crítica profunda, com vistas a não tornar tais proposições fragmentos didáticos que apenas conferem aos currículos e às suas práticas a aparência de inovação" (SILVA; COLONTONIO, 2014, p. 625). Tal exercício implica, inclusive, a compreensão dos significados que os elementos do trabalho, da cultura, da ciência e da tecnologia ocupam nas DCNEM. Nesse sentido, consideramos apropriado mencionar que:

\footnotetext{
Nomear trabalho, cultura, ciência e tecnologia como centro das propostas curriculares para o ensino médio exige mais do que a busca pelos significados de cada um dos elementos que o compõe, e ultrapassa o sentido de justificá-los ou legitimá-los no discurso sobre o currículo. Sinalizamos para o necessário desafio de se buscar, juntamente com os sujeitos jovens e adultos aos quais essas proposições se destinam, os significantes desses conceitos como forma de desvelá-los e explorá-los na história, nas relações de poder e nos interesses que circundam as relações sociais entre o trabalho, a ciência, a tecnologia na contemporaneidade. O texto normativo é expressão de uma prática social, o que torna igualmente relevante a compreensão das relações sociais que tensionam suas proposições, com vistas a superar sua limitação instrumental (SILVA; COLONTONIO, 2014, p. 626).
}

Compreender tais significados requer que os profissionais da educação, em uma relação dialógica, estudem e discutam as implicações dessa concepção em suas práticas pedagógicas. A formação ou autoformação dos professores é estratégica para que uma identidade profissional comprometida com uma educação emancipatória se constitua e institua. 
Por fim, tomamos para análise a Resolução MEC/CNE/CEB n. ${ }^{\circ}$ 6/2012, que define as Diretrizes Curriculares Nacionais para a Educação Profissional Técnica de Nível Médio (DCNEPTNM), e concluímos que, além dos aspectos já sublinhados na análise das DCNEB e DCNEM, nas DCNEPTNM há elementos relacionados ao percurso da formação profissional, ou seja, uma preocupação com a relação entre a formação e as demandas sociais, econômicas e ambientais, especialmente. Ressaltamos, ainda, a preocupação tanto com o reconhecimento dos sujeitos e suas diversidades, pessoas com deficiência, transtornos globais do desenvolvimento e altas habilidades, as pessoas em regime de acolhimento ou internação e em regime de privação de liberdade, quanto com o reconhecimento das identidades de gênero e étnico-raciais, assim como dos povos indígenas, quilombolas e populações do campo.

Portanto, considerando a necessidade de avançarmos nas análises as quais nos propusemos realizar neste estudo, verificamos com que frequência os descritores interculturalidade, inclusão, diversidade e emancipação aparecem nas diretrizes analisadas. Tais descritores foram eleitos pela centralidade contida nas concepções que os envolvem para uma educação comprometida com a redução das injustiças e, portanto, com a transformação social. Feita a análise, identificamos que o descritor interculturalidade não está presente em nenhuma das diretrizes; o descritor inclusão, por sua vez, aparece quatro vezes nas DCNEB, nenhuma vez nas DCNEM e uma vez nas DCNEPTNM; já o descritor emancipação aparece flexionado como emancipador e está presente uma única vez nas Diretrizes Curriculares Nacionais para a Educação Básica.

A presença do descritor inclusão, que aparece nas DCNEB, está ligada ao acesso, permanência e sucesso escolar, respeitando as diversidades dos públicos e contextos, ou seja, a qualidade social da escola (arts. $1 .^{\circ}, 4 .^{\circ}, 8^{\circ}$ e 9. ${ }^{\circ}$ ). Nas DCNEPTNM, por sua vez, o descritor inclusão aparece como sinônimo de inserção de dados, não havendo, portanto, relação com as reflexões aqui realizadas.

Nas DCNEB, o descritor diversidade aparece 11 vezes. É curioso notar que, na primeira vez que esse descritor aparece, ele está relacionado à construção de um projeto de nação, conforme segue. Vejamos:

Art. 3. ${ }^{\circ}$ As Diretrizes Curriculares Nacionais específicas para as etapas e modalidades da Educação Básica devem evidenciar o seu papel de indicador de opções políticas, sociais, culturais, educacionais, e a função da educação, na sua 
relação com um projeto de Nação, tendo como referência os objetivos constitucionais, fundamentando-se na cidadania e na dignidade da pessoa, o que pressupõe igualdade, liberdade, pluralidade, diversidade, respeito, justiça social, solidariedade e sustentabilidade (BRASIL, 2010, p. 2).

Ademais, o descritor é utilizado ainda outras dez vezes, sendo associado nove vezes à ideia de respeito à pluralidade e diversidade cultural em que a escola está inserida. A partir de tal presença, entendemos ser indispensável a inserção desses termos e fundamentalmente das concepções que os envolvem, tanto na organização e gestão das escolas (incluindo-se aqui a construção e implementação de suas propostas pedagógicas), quanto nas práticas pedagógicas dos profissionais da educação. É essencial, portanto, que a formação oferecida aos estudantes ultrapasse a lógica de alcançar o melhor desempenho cognitivo, mas que alcance também os aspectos socioemocionais, políticos, econômicos, culturais, identitários considerando o contexto em que a escola está inserida. Há uma inserção do termo diversidade atrelado às diferentes atividades de aprendizagem.

Observamos também que o termo diversidade aparece cinco vezes nas DCNEM. A primeira entrada está atrelada ao reconhecimento e à aceitação da diversidade e da realidade concreta dos sujeitos do processo educativo, das formas de produção, dos processos de trabalho e das culturas a eles subjacentes. A segunda entrada refere-se à oferta de uma formação que considere a diversidade e as características locais e especificidades regionais. A terceira entrada defende a necessidade de considerar a diversidade e a singularidade dos sujeitos do processo de ensino aprendizagem na concepção e implementação do projeto político pedagógico das escolas. A quarta menciona o reconhecimento e o atendimento da diversidade e diferentes nuances da desigualdade e da exclusão na sociedade brasileira. Na quinta e última vez, o termo é tratado como diferença regional, concernente à elaboração de uma proposta de expectativas de aprendizagem para os estudantes do ensino médio.

Nas DCNEPTNM, o descritor diversidade está presente em três situações. A primeira refere-se ao reconhecimento dos sujeitos e suas diversidades, mencionando as pessoas com deficiência, transtornos globais do desenvolvimento e altas habilidades, aquelas em regime de acolhimento ou internação e em regime de privação de liberdade (BRASIL, 2012b, p. 3). Na segunda, o descritor está relacionado ao "reconhecimento das diversidades das formas de produção, dos processos de trabalho e das culturas a eles subjacentes, as quais estabelecem novos paradigmas" (BRASIL, 2012b, p. 4). Na terceira vez, o descritor possui relação com o 
cumprimento das responsabilidades sociais das instituições que oferecem Educação Profissional, entre elas a promoção dos valores democráticos e respeito à diferença e à diversidade.

No tocante ao descritor emancipação, conforme mencionado, ele aparece uma única vez, no termo "emancipador", presente no $\S 3 .^{\circ}$ do art. 54 da Resolução CNE/CEB n. 4/2010, que trata da Gestão Democrática e Organização da Escola:

$\S 3 .^{\circ}$ No exercício da gestão democrática, a escola deve se empenhar para constituirse em espaço das diferenças e da pluralidade, inscrita na diversidade do processo tornado possível por meio de relações intersubjetivas, cuja meta é a de se fundamentar em princípio educativo emancipador, expresso na liberdade de aprender, ensinar, pesquisar e divulgar a cultura, o pensamento, a arte e o saber (BRASIL, 2010, p. 21)

A partir do estudo realizado e ponderando os propósitos deste texto, entendemos que as diretrizes analisadas apresentam potencialidade para subsidiar a elaboração de currículos e o desenvolvimento de práticas interculturais e inclusivas que impactem a construção de identidades descolonizadas, tanto de professores quanto de estudantes, de forma a contribuir para uma formação emancipatória dos sujeitos do processo educativo. Dizemos isso considerando que tanto o trabalho docente quanto as políticas educacionais, as relações entre professores e estudantes e o processo de apropriação dos conhecimentos historicamente acumulados em diálogo com o contexto em que os sujeitos do processo educativo estão inseridos constituem os currículos reais da escola e forjam a formação dos sujeitos. Tal formação pode estar comprometida com projetos societários distintos: aquele que está a serviço do sistema produtivo capitalista que defende, constrói e, por que não dizer, impõe currículos sob a perspectiva eurocêntrica e capitalcêntrica; ou aquele que defende os interesses da classe trabalhadora mais empobrecida e uma educação intercultural, inclusiva, que tenha como horizonte a emancipação dos sujeitos historicamente subalternizados pelo capital.

\section{CONSIDERAÇÕES FINAIS}

Ao finalizarmos nossas reflexões, trazemos presente o fato de que as Diretrizes 
Curriculares analisadas são documentos de caráter normativo e prescritivo dirigidos aos sistemas de ensino, aos profissionais de educação e aos estudantes e que alcançam toda a sociedade. São elas, portanto, que dão legitimidade à construção de currículos e práticas desenvolvidos pelos coletivos das escolas.

A partir da análise que realizamos, foi possível identificar que os conceitos e concepções presentes nesses documentos dialogam com os propósitos de uma formação integral que tem como horizonte a construção de identidades descolonizadas, tanto de professores quanto de estudantes. Tais conceitos e concepções, se apropriados pelos envolvidos no processo educativo, tendem a corroborar uma formação emancipatória dos sujeitos do processo educativo e, portanto, desobedientes epistemologicamente ao que historicamente vem dominando nossos currículos e práticas: uma formação eurocêntrica e capitalcêntrica.

A partir da reflexão acerca dos princípios das Diretrizes da Educação Básica, do Ensino Médio e da Educação Profissional Técnica de Nível Médio dos descritores interculturalidade, inclusão, diversidade e emancipação analisados neste texto, podemos afirmar que a concepção de uma educação intercultural, inclusiva e emancipatória permeia os textos dessas legislações. Ao contemplarem a defesa de uma educação de qualidade social, a educação como prática social e o exercício pleno da cidadania, por exemplo, temos elementos suficientes para sustentar que as atuais diretrizes da educação brasileira amparam legalmente a construção de currículos e práticas comprometidas com a construção de identidades descolonizadas de professores e estudantes.

\section{REFERÊNCIAS}

AFONSO, A. J. Autonomia das escolas. Revista Inovação do Instituto de Inovação Educacional, v. 12, n. 3, p. 121-137, 1999.

APPLE, M.; BEANE, J. (Org.). Escolas democráticas. São Paulo: Cortez, 1997. APPLE, M. W. Ideologia e Currículo. 3. Ed. Porto Alegre: Artmed, 2006.

BRASIL. Resolução n. ${ }^{\circ}$ 4, de 13 de julho de 2010. Define Diretrizes Curriculares Nacionais Gerais para a Educação Básica. Disponível em: http://portal.mec.gov.br/dmdocuments/rceb004_10.pdf. Acesso em: 20 nov. 2017. 
BRASIL. CNE/CEB. Resolução n. ${ }^{\circ}$ 2, de 30 de janeiro de 2012a. Define Diretrizes Curriculares Nacionais para o Ensino Médio. Disponível em: http://portal.mec.gov.br/index.php? option=com_content\&view=article\&id=17417\&Itemid=866. Acesso em: 13 nov. 2017.

BRASIL. CNE/CEB. Resolução n. ${ }^{\circ}$ 6, de 20 de setembro de 2012b. Define Diretrizes Curriculares Nacionais para a Educação Profissional Técnica de Nível Médio. Disponível em: $<$ http://portal.mec.gov.br/index.php? option=com_content\&view=article\&id=17417\&Itemid=866>. Acesso em: 10 nov. 2017.

BRASIL. Diretrizes Curriculares Nacionais Gerais da Educação Básica. Brasília: MEC, SEB, DICEI, 2013.

CANDAU, V. M. F. Cotidiano escolar e práticas interculturais. Cadernos de Pesquisa, v. 46. n. 161, p. 802-820, jul.-set. 2016.

CONTRERAS, J. A autonomia de professores. São Paulo: Cortez, 2002.

COPPETE, M. C.; FLEURI, R. M.; STOLTZ, T. Educação para a diversidade numa perspectiva intercultural. Revista Pedagógica, Unochapecó, ano 15, v. 1, n. 28, jan.-jun. 2012.

FERNANDES, S. R. S. Projetos educativos escolares e práticas alfabetizadoras emancipatórias: os contributos da Escola da Ponte de Portugal. Curitiba: CRV, 2016.

FLEURI, R. M. Intercultura e educação. Revista Brasileira de Educação, n. 23, maio-ago. 2003.

FLEURI, R. M.; COPPETE, M. C.; AZIBEIRO, N. E. In: OLIVEIRA, Lilian B. et al. (Org.). Culturas e diversidade religiosa na América Latina. Pesquisas e Perspectivas Pedagógicas. Blumenau: Editora Edifurb, 2009.

LANDER, E. (Org.). A colonialidade do saber: eurocentrismo e ciências sociais. Perspectivas latinoamericanas. Buenos Aires: Clacso, 2005. Disponível em: http://bibliotecavirtual.clacso.org.ar/. Acesso em: 20 jan. 2018.

LAWN, M. Os professores e a fabricação de identidades. In: Currículo sem Fronteiras, v. 1, n. 2, p. 117-130, jul./dez. 2001. Disponível em:

http://www.curriculosemfronteiras.org/vol1iss2articles/lawn.htm. Acesso em: 12 dez. 2017.

MIGNOLO, W. D. Desobediência epistêmica: a opção descolonial e o significado de identidade em política. Cadernos de Letras da UFF - Dossiê: Literatura, língua e identidade, n. 34, p. 287-324, 2008.

SANTOMÉ, J. T. Currículo escolar e justiça social: o cavalo de Troia da educação. Porto Alegre: Penso, 2013. 
SILVA, F. L. G. R. Identidade profissional dos professores da educação profissional técnica de nível médio no Brasil e em Santa Catarina: desafios para a sua formação. 2014. Tese (Doutorado em Educação) - Universidade Federal de Santa Catarina (UFSC), Florianópolis.

SILVA, M. R.; COLONTONIO, E. M. As Diretrizes Curriculares Nacionais para o Ensino Médio e as proposições sobre trabalho, ciência, tecnologia e cultura reflexões necessárias. Revista Brasileira de Educação, v. 19, n. 58, p. 611-628, jul.-set. 2014.

WALSH, C. Interculturalidad crítica y pedagogia de-colonial: apuestas (des)de el in-surgir re-existir y re-vivir. 2012. Disponível em:

http:/www.antropologias.org/rpc/files/downloads/2010/09/Catherine-Walsh-Interculturalidadcr\%C3\%ADtica-y-pedagog\%C3\%ADa-de-colonial.pdf. Acesso em: 10 nov. 2017. 